\title{
Anticorrosive Properties of Poly(o-phenylenediamine)/ZnO Nanocomposites Coated Stainless Steel
}

\author{
Aisha Ganash \\ Chemistry Department, Faculty of Science, King Abdulaziz University P.O. Box 42805, Jeddah 21551, Saudi Arabia \\ Correspondence should be addressed to Aisha Ganash; aganash@kau.edu.sa
}

Received 21 February 2014; Accepted 8 April 2014; Published 29 April 2014

Academic Editor: John Z. Guo

Copyright (C) 2014 Aisha Ganash. This is an open access article distributed under the Creative Commons Attribution License, which permits unrestricted use, distribution, and reproduction in any medium, provided the original work is properly cited.

Poly(o-phenylenediamine) and poly(o-phenylenediamine)/ZnO ( $\mathrm{PoPd} / \mathrm{ZnO})$ nanocomposites coating were prepared on type304 austenitic stainless steel (SS) using $\mathrm{H}_{2} \mathrm{SO}_{4}$ acid as electrolyte by potentiostatic methods. Fourier transforms infrared spectroscopy and scanning electron microscopy techniques were used to characterize the composition and structure of PoPd/ZnO nanocomposites. The corrosion protection of polymer coatings ability was studied by $E_{\text {ocp }}$-time measurement, anodic and cathodic potentiodynamic polarization and impedance techniques in $3.5 \% \mathrm{NaCl}$ as corrosive solution. It was found that $\mathrm{ZnO}$ nanoparticles improve the barrier and electrochemical anticorrosive properties of poly(o-phenylenediamine).

\section{Introduction}

Corrosion is an undesirable natural process that arises since the use of metallic materials; therefore, serious efforts to prevent this phenomenon are ongoing through this century. Three approaches are commonly applied to reduce the rate of corrosion including cathodic protection, anodic protection (passivation), and application of barrier coatings [1]. Protective coatings have been widely used for metal corrosion control. The use of conducting polymers for the inhibition of corrosion is an area which is very recently gaining increasing attention [2].

A successful electropolymerization on active metal generally requires a passive layer to prevent the dissolution of the metal and at the same time to oxidize monomers into polymers. Sometimes, a primer polymer coating has also been needed to ensure a firm binding deposit onto the base metal. Polyaniline, polypyrrole, and their derivatives have been widely investigated because of the low potential for polymer formation and easy preparation and stability of the formed films. It was shown that ring-substituted conducting polymers [3] such as poly(o-anisidine), poly(o-toluidine), poly(m-toluidine), and poly(o-chloroaniline) can improve the corrosion performance in aggressive environment like straight line polymers such as PANI and PPy. Series of studies have reported that polymer films based on thiophene [4], o-phenylenediamine [5], N-methyl pyrrole [6], 2,5dimethoxyaniline [7], and other heterocyclic compounds reduce the corrosion rate of steel and iron in sulfuric acid and chloride solutions. Phenylenediamine PoPd is considered as one of the most investigated conducting polymers and also attracted much interest in many studies with various practical applications because of its high conductivity, outstanding air stability, and special physical, chemical properties compared with other conducting polymers [5, 8-12].

Conducting polymer/inorganic oxide nanocomposites have recently attracted great attention due to their unique microstructure, physiochemical and electrooptical properties, and a wide range of their potential usage in battery cathodes and in the construction of nanoscopic assemblies in sensors and microelectronics $[13,14]$. It is believed that, with the development of material science, $\mathrm{ZnO}$ has found further applications in many fields $[15,16]$. $\mathrm{ZnO}$ is a new multifunctional inorganic material, which has stable physical and chemical properties, high oxidation activity, ease of synthesis, and widely potential applications in many research areas [17]. ZnO plays an important role in the chemical industry, electronics, optics, and many other areas because 
of its catalysis, optical, magnetic, and mechanical special features [18]. Thus, the nanocomposites consisting of polymer and $\mathrm{ZnO}$ have attracted lots of interest in their excellent properties and potential applications $[17,19,20]$. Other researchers reported that the presence of $\mathrm{ZnO}$ nanoparticles (NPs) can affect the electropolymerization process where $\mathrm{ZnO}$ acts as an incorporating agent [21]. Since composites made from inorganic nanomaterials exhibit indispensable constancy, this design can be effectively employed for specific applications. A number of researches investigated conducting polymer/ $\mathrm{ZnO}$ nanocomposites, and several research groups have focused their research on the investigation of $\mathrm{PPy} / \mathrm{ZnO}$ nanocomposites and their applications. Hosseini et al. synthesized $\mathrm{PPy} / \mathrm{ZnO}$ nanocomposites by electrochemical method, in which they found that pure PPy film could not protect the mild steel perfectly but the introduction of nanosized $\mathrm{ZnO}$ into the PPy system has dramatically increased the corrosion resistance of mild steel [19]. Joshi et al. prepared $\mathrm{ZnO}$ nanowires modified PPy films by drop casting glass substrates using colloidal solution containing PPy and $\mathrm{ZnO}$ nanowires in different weight percentages, and they found that the composites had highly selective and sensitive properties used as chlorine sensors [17]. $\mathrm{PPy} / \mathrm{ZnO}$ composites film could be also synthesized by using electropolymerization method and the composite film exhibited an improved xanthine biosensing [20]. Mahmoudian et al. studied the effect of the addition of $\mathrm{ZnO}$ nanoparticles in electropolymerization of poly(N-methyl pyrrole ) on steel substrates from oxalic acid [22]. Chen et al. found that the $\mathrm{PPy} / \mathrm{ZnO}$ nanocomposites coating had relatively better charge-carrying capacity, better conductivity, and higher corrosion protection properties than that of pure PPy [23]. PPy/ZnO composites film could be also synthesized by using electropolymerization method and the composite film exhibited an improved xanthine biosensing [20]. Nanostructured core-shell ZnO/PANI composite system was successfully synthesized by in situ polymerization method and it was found that $\mathrm{ZnO}$ nanoparticles improve the barrier and electrochemical anticorrosive properties of polyaniline and the addition of polyvinyl chloride increases the barrier effect of polyaniline coating [24].

To the best of our knowledge, hitherto no literature has been published for PoPd/ZnO nanocomposites coating as corrosion prevention for stainless steel in chloride medium. For this, recent work involves electrochemical synthesis of nanocomposites coating consisting of PoPd and $\mathrm{ZnO}$ by potentiostatic technique on 304-stainless steel material.

The structure and properties of PoPd/ZnO nanocomposites coating were studied and the anticorrosive properties of $\mathrm{PoPd} / \mathrm{ZnO}$ nanocomposites coating on metal sample were investigated in $3.5 \% \mathrm{NaCl}$ at room temperature.

\section{Experimental Procedure}

2.1. Materials and Electrochemical Cell. O-Phenylenediamine (98\%, Fisher) was used as received. Sulfuric acid (>98\%, Fluka) was used for electropolymerization. $\mathrm{ZnO}$ nanoparticles with an average diameter $<100 \mathrm{~nm}$ were purchased from Aldrich. An electrochemical cell with a three-electrode was used for electrochemical measurements; $304 \mathrm{SS} \operatorname{rod}(6 \mathrm{~mm}$ in diameter), a platinum sheet, and a Metrohm $\mathrm{Ag} / \mathrm{AgCl}$ electrode (in $3 \mathrm{M} \mathrm{KCl}$ ) were used as working, counter, and reference electrodes, respectively. The chemical composition (Wt. \%) of the 304-stainless steel used in this study was $0.03 \mathrm{C}, 0.02 \mathrm{~S}, 0.041 \mathrm{P}, 0.43 \mathrm{Si}, 8.08 \mathrm{Ni}, 0.34 \mathrm{Mo}, 1.45 \mathrm{Mn}, 0.50 \mathrm{Cu}$, $18.23 \mathrm{Cr}, 0.82 \mathrm{~N}$, and $0.13 \mathrm{Co}$. The 304 -stainless steel substrates were polished with a series of emery papers, followed by thorough rinsing in acetone and double distilled water, and dried in air. Prior to any experiment, the substrates were treated as described and freshly used with no further storage.

2.2. Electrodeposition of Polymer Composite on 304 SS. Electrochemical experiments were carried out using an AUTOLAB PGSTAT 30 potentiostat/galvanostat connected to personal computer through a USB electrochemical interface. The electrodeposition of PoPd on 304 SS electrodes was carried out potentiostatically (change of current versus time at constant value of potential of $1.2 \mathrm{~V}$ versus $\mathrm{Ag} / \mathrm{AgCl}$ ). Electrodeposition experiments were conducted at room temperature up to $30 \mathrm{~min}$ (1800 s), using a freshly prepared solution containing $1 \mathrm{M}$ sulfuric acid and $0.15 \mathrm{M}$ o-phenyelendiamine in the presence and absence of $30 \mathrm{mg} \mathrm{ZnO}$ nanoparticles for each deposition. At the end of each experiment, the working electrode (304 SS) was coated by reddish brown thin film of $\mathrm{PoPd}$ and $\mathrm{PoPd} / \mathrm{ZnO}$ nanocomposites.

For characterization of polymer layer the Fourier transforms infrared (FTIR) spectra of the polymer film were measured using a PerkinElmer FTIR spectrometer. The morphology of the polymer film was investigated by scanning electron microscopy (SEM) using a Jeol JSM-6360LVSEM.

2.3. Corrosion Tests. The corrosion resistance property of bare and coated stainless steel was evaluated in $3.5 \% \mathrm{NaCl}$ at room temperature by open circuit potential $E_{\text {ocp }}$-time curves, Tafel polarization, and electrochemical impedance spectroscopy (EIS).

The polarization curves were recorded with a scan rate of $1 \mathrm{mV} \mathrm{s}^{-1}$, where the initial potential was the corrosion potential value reached after one hour of exposure time. The polarization curves were obtained starting from the open circuit potential (OCP) and varying the potential up to $200 \mathrm{mV}$ in anodic branch of the Tafel plot and down to $-200 \mathrm{mV}$ cathodic branch of the Tafel plot.

Electrochemical impedance spectroscopy data were obtained at corrosion potential over a frequency range from $5 \times 10^{4} \mathrm{~Hz}$ to $0.1 \mathrm{~Hz}$ using $\mathrm{AC}$ amplitude of $10 \mathrm{mV}$ around the open circuit potential by using the FRA software. All electrochemical experiments were performed and the data were collected after one hour immersion for 304 SS in corrosive solution at room temperature.

The analysis of the impedance spectra was done by fitting the experimental results to equivalent circuits using the nonlinear least-square fitting procedure. The quality of fitting to equivalent circuit was judged by Chi-squared $\left(\chi^{2}\right)$ values of $10^{-3}$ or less. 


\section{Results and Discussion}

3.1. Electropolymerization of Polymer Composite Films on 304 SS. Figure 1 depicts the potentiostatic deposition recorded of o-phenylenediamine on 304 SS from $1 \mathrm{M}$ sulfuric acid and $0.15 \mathrm{M}$ o-phenylenediamine in the presence and absence of $30 \mathrm{mg} \mathrm{ZnO}$ nanoparticles in order to compare the structure and anticorrosive property of polymer composite coating with pure PoPd; the figure represents current-time transit during electropolymerization at potential $1.2 \mathrm{~V}$ for $1800 \mathrm{~s}$. It can be seen that the time taken for formation of electropolymerized coating is very short.

The comparison between Figures 1(a) and 1(b) shows that the decrease of current density of the monomer oxidation in the presence of $\mathrm{ZnO}$ is much more than that in the absence of $\mathrm{ZnO}$. The decrease of electrolyte conductivity due to the presence of $\mathrm{ZnO}$ [25] and the increasing resistance of the polymer coating during the polymerization process are the reasons for this phenomenon. In addition, $\mathrm{ZnO}$ might act as a barrier and reduce direct interaction between monomers and the steel surface as working electrode [22].

3.2. Spectroscopic Characterization. The electropolymerized PoPd in the presence and absence of $\mathrm{ZnO}$ on steel surface was scraped off and Fourier transform infrared spectroscopy (FTIR) spectra of the polymer powders were recorded in Figure 2. Curve (a) gives the FT-IR spectrum of pure PoPd in which the absorption peaks at $1502 \mathrm{~cm}^{-1}$ and $1582 \mathrm{~cm}^{-1}$ are attributed to the $\mathrm{C}=\mathrm{C}$ stretching mode of benzonoid and quinoid rings in PoPd chains, respectively [24]. The peaks at $1311 \mathrm{~cm}^{-1}$ and $3437 \mathrm{~cm}^{-1}$ are assigned, respectively, to the $\mathrm{C}-\mathrm{N}$ and $\mathrm{N}-\mathrm{H}$ stretching bonds of secondary amine group. In the curve (b) for PoPd/ZnO nanocomposites coating, the peak at $579 \mathrm{~cm}^{-1}$ came from $\mathrm{ZnO}$ bond in $\mathrm{ZnO}$ nanoparticles [26]. The peak at $3437 \mathrm{~cm}^{-1}$ for nanocomposite (Figure 2(b)) is stronger than that of in pure PoPd (Figure 2(a)). This may be due to the overlapping of peak related to the stretching of $\mathrm{O}_{-}$ $\mathrm{H}$ bonding between $\mathrm{ZnO}$ nanoparticles and PoPd molecules with the absorption peak of $\mathrm{N}-\mathrm{H}$ bond in PoPd chains [27]. The absorption peaks coming from $\mathrm{ZnO}$ were detected in $\mathrm{PoPd} / \mathrm{ZnO}$ indicating that the $\mathrm{ZnO}$ nanoparticles had loaded in PoPd successfully.

3.3. Morphological Characterization. Figure 3(a) shows SEM image of PoPd and PoPd/ZnO nanocomposites coating ((b, $c$, and d) at different magnification), respectively. Other researchers reported that a net of broad lines characterizes the morphology of PoPd layers. These lines are similar to the conductive lines that appeared in transparent films of ladderconductive polymer benzimidazobenzophenathroline [28].

Figures 3(b), 3(c), and 3(d) are consisting of white granular with size of around $100 \mathrm{~nm}$. After $\mathrm{ZnO}$ nanoparticles were introduced into the composite system, the $\mathrm{ZnO}$ particles during synthesis were distributed randomly into the net lines among PoPd, which made the PoPd coating dense and preferred to prevent the direct contact of corrosive solution.

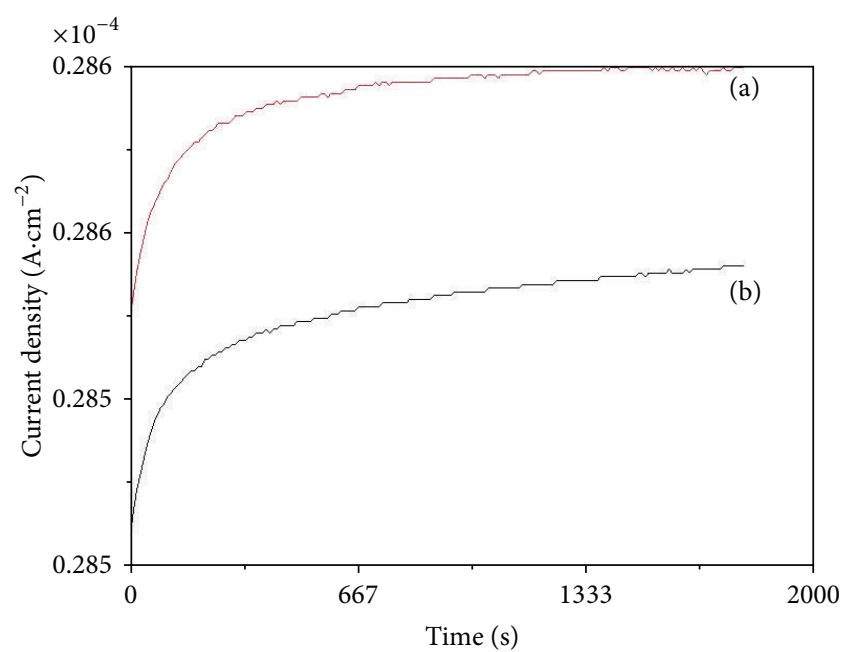

FIgURE 1: Potentiostatic polymerization of pure PoPd (a) and $\mathrm{PoPd} / \mathrm{ZnO}$ nanocomposites coating (b) at potential $1.2 \mathrm{~V}$ for $1800 \mathrm{~s}$.

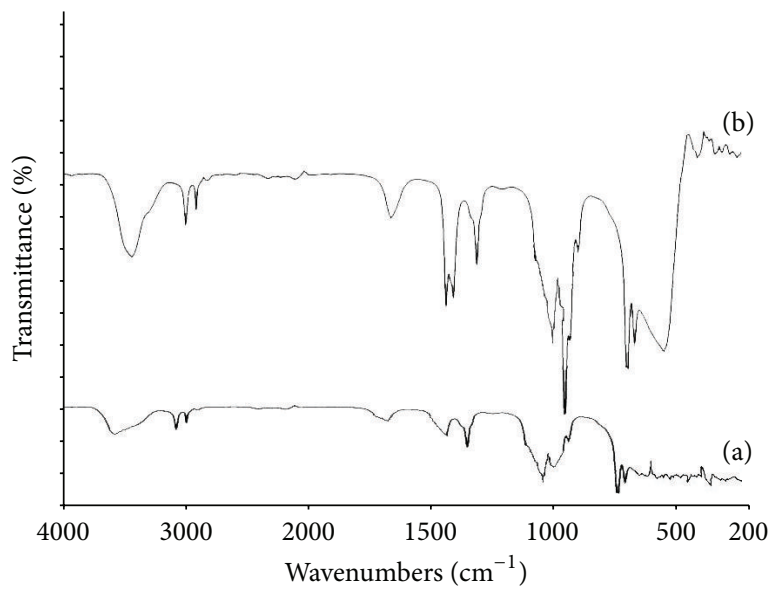

Figure 2: FTIR spectra $\left(4000-200 \mathrm{~cm}^{-1}\right)$ of pure PoPd (a) and $\mathrm{PoPd} / \mathrm{ZnO}$ nanocomposites coating (b).

\subsection{Comparison in Terms of Protection of 304 SS}

3.4.1. $E_{\text {opc }}$-Time Measurements. $E_{\text {ocp }}$-time curves are generally used to understand the efficiency of the conducting polymer during corrosion tests as the kinetics of reduction reactions of $\mathrm{O}_{2}$ and $\mathrm{H}_{2} \mathrm{O}$ depends on $E_{\text {ocp }}$ value of the bare metal. When a metal is coated with a highly doped conducting polymer and as long as the conducting polymer remains in its conductive state, $E_{\text {ocp }}$ value of the conducting polymer/metal system is always above that of the bare metal electrode. When the conducting polymer is reduced, the potential value drops to a lower value [29]. Figure 4 shows $E_{\text {ocp }}$-time curves of bare 304 SS electrode, pure PoPd, and $\mathrm{PoPd} / \mathrm{ZnO}$ nanocomposite in chloride solution. As seen from Figure 4, in case of bare 304 SS potential values slightly increased toward the more positive value due to the formation of corrosion products including oxides on the surface, the potential values of pure PoPd coating decreased rapidly toward the more negative direction due to the attack by 


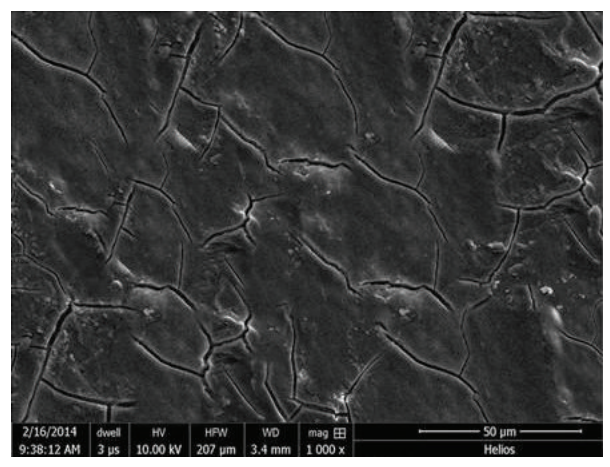

(a)

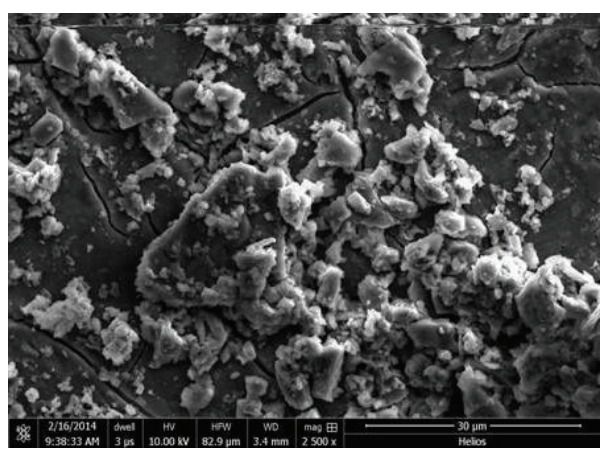

(c)

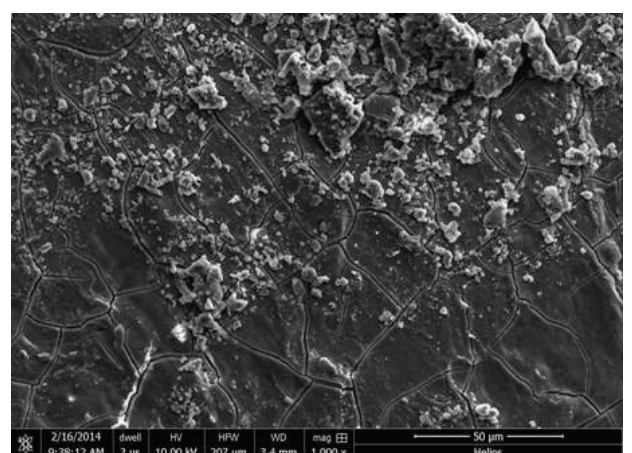

(b)

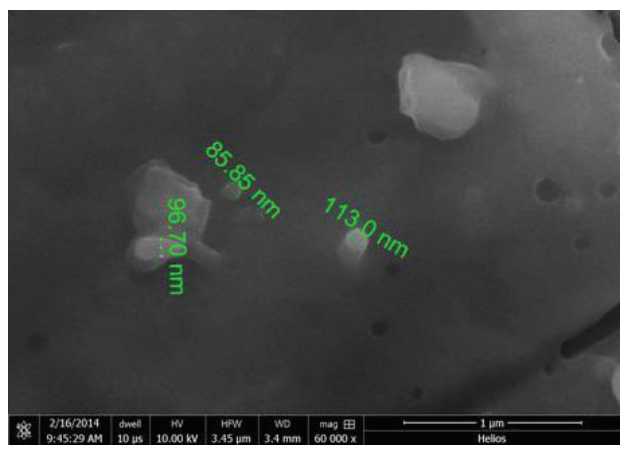

(d)

FIgURe 3: SEM images of pure PoPd (a) and PoPd/ZnO nanocomposites coating (b), (c), and (d).

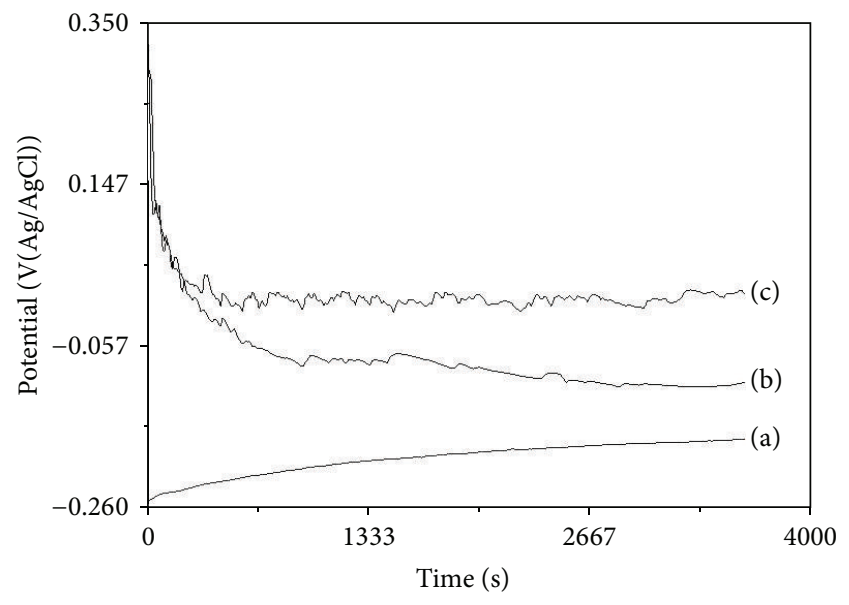

FIGURE 4: Potential-time behaviour of bare 304 SS (a), pure PoPd (b), and $\mathrm{PoPd} / \mathrm{ZnO}$ nanocomposites coating (c) in $3.5 \% \mathrm{NaCl}$ solution.

the aggressive ions that were present in the solution. This implies that significant amounts of electrolyte solution have passed through coating and reached the surface of underlying metal, causing the start of corrosion process [30]. The $E_{\text {ocp }}$ value of $\mathrm{PoPd} / \mathrm{ZnO}$ nanocomposite coated SS is more anodic than that of pure PoPd coating during exposure time and this suggests that this coating polymer maintains its oxidative state and provides corrosion protection to the metal [31]. In addition, this shows that $\mathrm{O}_{2}$ reduction reaction (cathodic reaction) takes place at the polymer surface. In other words, this confirms the displacement of the electrochemical interface (e.g., from metal-electrolyte interface to polymerelectrolyte interface) [32]. The constant value of open circuit potential of $\mathrm{PoPd} / \mathrm{ZnO}$ nanocomposite under the given experimental conditions indicates a barrier behavior of the $\mathrm{PoPd} / \mathrm{ZnO}$ nanocomposite, which limits the diffusion of the corrosive species towards the underlying steel substrate. Hosseini et al. found that Polypyrrole/ $\mathrm{ZnO}$ nanocomposite coating was able to keep its excellent barrier property and there was no evidence for notable corrosion of underlying metal [19].

\subsubsection{Potentiodynamic Polarization Measurements.} Although the Tafel extrapolation method is usually insufficient for understanding the protective properties of electroactive conducting polymer coatings, this method may be used to compare corrosion performances of various polymer coating types [33]. Figure 5 shows Tafel curves of bare 304 SS electrode, pure PoPd, and PoPd/ZnO nanocomposite. The values of corrosion potential $\left(E_{\text {corr }}\right)$, corrosion current density $\left(i_{\text {corr }}\right)$, anodic and cathodic Tafel constants, and corrosion rate (CR) are obtained from GPES software and reported in Table 1.

However, both redox process of the electroactive conducting polymer and the corrosion of steel must have contributed to the $i_{\text {corr }}$ values $[34,35]$. Therefore, $i_{\text {corr }}$ represents the exchange in the current density values, here. The data in Table 1 shows that current density represented as $i_{\text {corr }}$ 
TABle 1: Polarisation parameters for bare 304 SS, pure PoPd, and PoPd/ZnO nanocomposite.

\begin{tabular}{lccc}
\hline Polarization parameters & Bare 304 SS & Pure PoPd & PoPd/ZnO nanocomposite \\
\hline$E_{\text {corr }} / V$ & -0.200 & -0.113 & -0.036 \\
$j_{\text {corrosion }} / \mu \mathrm{A} \mathrm{cm}^{-2}$ & 0.870 & 0.036 & 0.010 \\
ba $\left(\mathrm{mV} \mathrm{dec}^{-1}\right)$ & 298 & 101 & 112 \\
bc $\left(\mathrm{mV} \mathrm{dec}^{-1}\right)$ & 79 & 70 & 83 \\
Corrosion rate $/ \mu$ m year & 1.91 & 0.835 & 0.236 \\
\hline
\end{tabular}

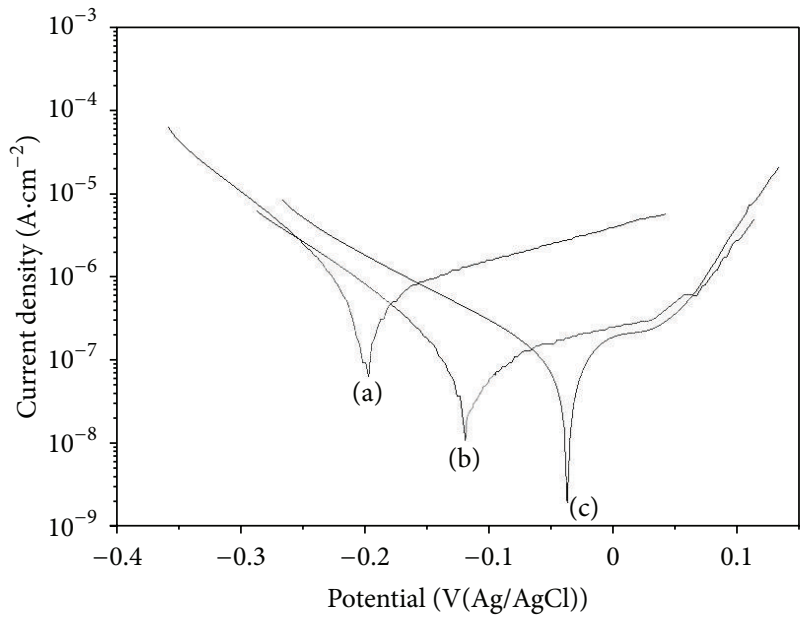

Figure 5: Tafel plot of bare 304 SS (a), pure PoPd (b), and PoPd/ZnO nanocomposites coating (c) in $3.5 \% \mathrm{NaCl}$ solution.

for pure PoPd and PoPd/ZnO nanocomposite is less than bare 304 SS. When the pure PoPd coating is compared with $\mathrm{PoPd} / \mathrm{ZnO}$ nanocomposite, we found the value of $i_{\text {corr }}$ in case of composites is less $\left(i_{\text {corr }}=0.010 \mu \mathrm{A} \mathrm{cm}^{-2}\right)$ than the value for PoPd coating $\left(i_{\text {corr }}=0.036 \mu \mathrm{Acm}^{-2}\right)$ indicating the highest corrosion protection properties. The decrease in the corrosion current indicates the formation of protective films on metal surfaces. This effect increases in the presence of $\mathrm{ZnO}$ nanocomposite. This result shows that PoPd and PoPd/ZnO nanocomposite inhibit the anodic reaction by acting as a barrier layer between electrode surface and corrosion environment.

Similar observation was also reported by Mahmoudian et al. [22]. Also by looking to the value of $E_{\text {corr }}$, the analysis of data shows the increase in the positivity in this order:

PoPd/ZnO nanocomposite $>$ pure PoPd $>$ Bare 304 SS.

It is now apparent that the conducting polymer accepts electrons from the metal and gives them to oxygen. This reaction generates the formation of a passive oxide layer at the polymer/metal interface, which lowers the corrosion rate and shifts the $E_{\text {corr }}$ to values that are more positive. The result of the potentiodynamic polarization measurements for the PoPd coating shows a shift in the $E_{\text {corr }}$ to more positive value and reduces the corrosion rate of SS. The positive shift in $E_{\text {corr }}$ indicates the protection of the metal surface by the polymer layer. Thus, the protection effect of polymer layer
TAble 2: Impedance parameters for pure PoPd and PoPd/ZnO nanocomposite.

\begin{tabular}{lcc}
\hline EIS parameters & Pure PoPd & PoPd/ZnO nanocomposite \\
\hline $\mathrm{Rs} / \Omega \mathrm{cm}^{2}$ & 14.05 & 10.44 \\
$\mathrm{Rf} / \mathrm{k} \Omega \mathrm{cm}^{2}$ & 20.96 & 8.38 \\
$\mathrm{Rct} / \Omega \mathrm{cm}^{2}$ & 507 & 211.4 \\
Qf- $Y\left(\mu \mathrm{F} \mathrm{cm}{ }^{-2}\right)$ & 145.6 & 210.7 \\
Qf- $n_{1}$ & 0.945 & 0.894 \\
Qdl- $Y\left(\mu \mathrm{F} \mathrm{cm}^{-2}\right)$ & 636 & 2148 \\
Qdl- $n_{2}$ & 1.00 & 0.759 \\
\hline
\end{tabular}

seems to be related to its passivation effect as well as its barrier behavior. The potentiodynamic polarization measurement of $\mathrm{PoPd} / \mathrm{ZnO}$ nanocomposite coating exhibits a shift in the $E_{\text {corr }}$ to a more positive value $(-0.036 \mathrm{~V})$ and reduces the corrosion rate of SS. In this case, the PoPd/ZnO nanocomposite coating acts as the more effective barrier as it is more stable and corrosion protective in chloride solution [36].

The positive shift in $E_{\text {corr }}$ confirms that the 304 SS covered by PoPd/ZnO nanocomposite coating depressed the anodic current of the corrosion reaction and offered greater resistance to corrosion [37].

As a result, the introduction of $\mathrm{ZnO}$ nanoparticles into to PoPd coatings led to exhibiting high corrosion protection properties. Similar result was obtained by Chen et al., in which they found that the insertion of $\mathrm{ZnO}$ nanoparticles improved the corrosion properties of polypyrrole [23]. It can be concluded that both electrochemical protection and barrier effects cause the corrosion protection of the composite coatings. The electrochemical protection is caused by the increase of the corrosion potential and the formation of a passive layer on the metal surface.

3.4.3. Electrochemical Impedance Spectroscopy Study. Figure 6 shows the Nyquist impedance curves of PoPd in the presence and absence of $\mathrm{ZnO}$ nanoparticles coated 304 SS electrodes. These experimental Nyquist impedance curves were fitted well to the equivalent circuit models inserted in Figure 6. These equivalent circuit models consist of solution resistance $\left(R_{s}\right)$, charge transfer resistance $\left(R_{\mathrm{ct}}\right)$, pore resistance for the coating $\left(R_{\text {pore }}\right)$, constant-phase element for double layer $\left(\mathrm{CPE}_{\mathrm{dl}}\right)$, and constant-phase element for the coating film $\left(\mathrm{CPE}_{c}\right)$. Here, constant-phase element (CPE) is used instead of the capacitance (C) to define the homogeneities in the system $[38,39]$. The fitting results of pure 


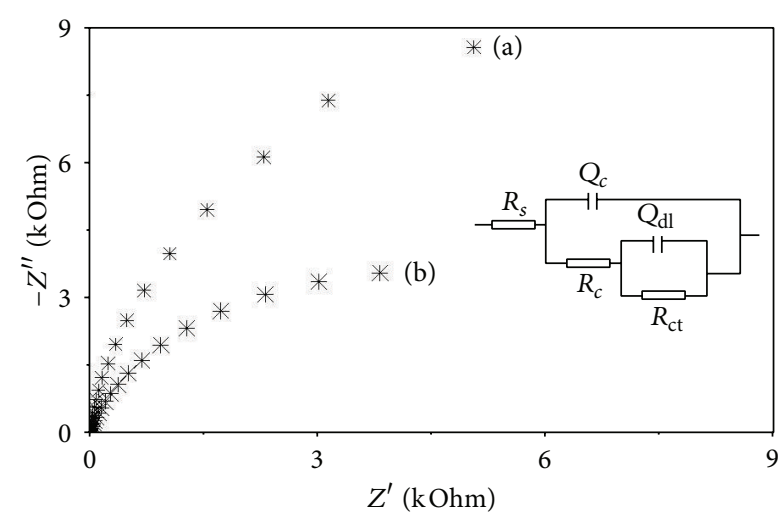

Figure 6: Nyquist plot pure PoPd (a) and PoPd/ZnO nanocomposites coating (b) in $3.5 \% \mathrm{NaCl}$ solution.

PoPd coating and PoPd/ZnO nanocomposite were tabulated in Table 2.

The film resistance value obtained for PoPd/ZnO nanocomposite was relatively low with respect to pure PoPd coating, which might be related to the electronic distribution channels of PoPd/ZnO nanocomposite [23].

The charge-transfer resistance value for PoPd/ZnO nanocomposite was lower than that of pure PoPd coating, which was associated with the surface morphology of PoPd/ZnO nanocomposite coating. Introduced $\mathrm{ZnO}$ nanoparticles in the polymer matrix lead to the decrease of the resistance for charge transfer during electrochemical reaction and thus charge transfer resistance of the entire electrode system due to the increase of the surface area. The film capacitance of PoPd/ZnO nanocomposite coating was found to be higher than that of pure PoPd. The results showed that PoPd/ZnO nanocomposite coating had better conductivity and charge storage capability [23]. Other authors reported the effect of the nanosize additives to improve the anticorrosion electrochemical barrier layer properties of polymers for diffusion of solvent [40-43]. The increase of PoPd surface area in the reaction medium is one of the advantages of the polymerization of PoPd in the presence of nanoparticles. One of the special properties of electroactive polymers is their ability to interact with the ions liberated during the corrosion reaction of steel in the presence of $\mathrm{Cl}^{-}$ion [44-46]. So, their performance increases with the increase of surface area.

3.4.4. The Mechanism of Protection and the Role of $\mathrm{ZnO}$. The electroactive organic coatings could provide anodic protection to stainless steel, by reducing themselves and stabilizing the more protective oxide formation. This behavior must have enhanced the passivation and accelerated the repair of passivity when it is broken [47]. It was shown [48] that the undoping process of conducting polymer works as a cathodic reaction, whereas the metal oxidation acts as an anodic reaction. This process may result in the positive shift of corrosion potential by forming a passive film at the metalpolymer interface.

The formed passive film on the surface protects the steel from corrosion and maintains the doping state of the polymer. The conducting polymer can also be reoxidized by atmospheric or dissolved oxygen as the reaction. Therefore, reoxidation of the conducting polymer is necessary for the polymer to continue in its role as electroactive coating

$$
\text { poly }^{0}+\frac{n}{4} \mathrm{O}_{2}+n \mathrm{H}^{+} \longrightarrow \text { poly }^{n+}+\frac{n}{2} \mathrm{H}_{2} \mathrm{O}
$$

The equation obviously shows the importance of oxygen reduction reaction of the polymer surface. Introducing $\mathrm{ZnO}$ in the nanocomposite increases the surface area of nanocomposite and this leads to increasing the surface area of PoPd; this can increase the ability of the PoPd/ZnO nanocomposite coating to interact with the ions liberated during corrosion reaction and/or it causes an increase in the rate probability for the occurrence of cathodic reduction of oxygen on the PoPd and enhances effectively the polymer oxidation and the formation of the oxide film. In addition, the incorporated $\mathrm{ZnO}$ nanoparticels also enhance the passivation of the coated SS in acidic solutions.

\section{Conclusion}

Pure PoPd and PoPd/ZnO nanocomposite coating were successfully electrodeposited on 304 SS by potentiostatic method. SEM shows that $\mathrm{ZnO}$ incorporated in polymer matrix affect the polymer morphology and increase the surface area of PoPd.

The existence of $\mathrm{ZnO}$ nanoparticles within the coating increases the anticorrosion effect on metal and this is due to catalyzing oxygen reduction on polymer surface and increases its ability to plug some pores and defects; thus the $R_{\mathrm{po}}$ increases. In other words, the comparison between corrosion performances of pure PoPd and PoPd/ZnO nanocomposite coating has shown that $\mathrm{PoPd} / \mathrm{ZnO}$ nanocomposite coating could provide much better protection to SS for considerable periods in chloride solution.

\section{Conflict of Interests}

The author declares that there is no conflict of interests regarding the publication of this paper.

\section{References}

[1] A. Olad and B. Naseri, "Preparation, characterization and anticorrosive properties of a novel polyaniline/clinoptilolite nanocomposite," Progress in Organic Coatings, vol. 67, no. 3, pp. 233-238, 2010.

[2] R. Manickavasagam, K. J. Karthik, M. Paramasivam, and S. V. Iyer, "Poly(styrene sulphonic acid)-doped polyaniline as an inhibitor for the corrosion of mild steel in hydrochloric acid," Anti-Corrosion Methods and Materials, vol. 49, no. 1, pp. 19-26, 2002.

[3] D. Sazou, "Electrodeposition of ring-substituted polyanilines on Fe surfaces from aqueous oxalic acid solutions and corrosion protection of Fe," Synthetic Metals, vol. 118, no. 1-3, pp. 133-147, 2001.

[4] U. Rammelt, P. T. Nguyen, and W. Plieth, "Protection of mild steel by modification with thin films of polymethylthiophene," Electrochimica Acta, vol. 46, no. 26-27, pp. 4251-4257, 2001. 
[5] S. S. Abd El Rehim, S. M. Sayyah, M. M. El-Deeb, S. M. Kamal, and R. E. Azooz, "Poly(o-phenylenediamine) as an inhibitor of mild steel corrosion in $\mathrm{HCl}$ solution," Materials Chemistry and Physics, vol. 123, no. 1, pp. 20-27, 2010.

[6] T. Tüken, G. Tansuğ, B. Yazici, and M. Erbil, "Poly(N-methyl pyrrole) and its copolymer with pyrrole for mild steel protection," Surface and Coatings Technology, vol. 202, no. 1, pp. 146154, 2007.

[7] V. Patil, S. R. Sainkar, and P. P. Patil, "Growth of poly(2,5dimethoxyaniline) coatings on low carbon steel," Synthetic Metals, vol. 140, no. 1, pp. 57-63, 2004.

[8] P. Muthirulan and N. Rajendran, "Poly(o-phenylenediamine) coatings on mild steel: electrosynthesis, characterization and its corrosion protection ability in acid medium," Surface and Coatings Technology, vol. 206, no. 8-9, pp. 2072-2078, 2012.

[9] A. A. Hermas, Z. X. Wu, M. Nakayama, and K. Ogura, "Passivation of stainless steel by coating with poly (o -phenylenediamine) conductive polymer," Journal of the Electrochemical Society, vol. 153, no. 6, pp. B199-B205, 2006.

[10] L. F. D’Elia, R. L. Ortíz, O. P. Márquez, J. Márquez, and Y. Martínez, "Electrochemical deposition of poly(o-phenylenediamine) films on type 304 stainless steel," Journal of the Electrochemical Society, vol. 148, no. 4, pp. C297-C300, 2001.

[11] R. Mazeikiene and A. Malinauskas, "The stability of poly(ophenylenediamine) as an electrode material," Synthetic Metals, vol. 128, no. 2, pp. 121-125, 2002.

[12] M. Düdükcü, "The electrochemical synthesis of poly(ophenylenediamine) on stainless steel and its corrosion protection ability in $3.5 \% \mathrm{NaCl}$ solution," Research on Chemical Intermediates, vol. 39, no. 8, pp. 3641-3647, 2013.

[13] R. Gangopadhyay and A. De, "Conducting polymer nanocomposites: a brief overview," Chemistry of Materials, vol. 12, no. 3, pp. 608-622, 2000.

[14] Y.-C. Liu, J.-M. Huang, C.-E. Tsai, T. C. Chuang, and C.-C. Wang, "Effect of $\mathrm{TiO}_{2}$ nanoparticles on the electropolymerization of polypyrrole," Chemical Physics Letters, vol. 387, no. 1-3, pp. 155-159, 2004.

[15] S. Roux, G. J. A. A. Soler-Illia, S. Demoustier-Champagne, P. Audebert, and C. Sanchez, "Titania/polypyrrole hybrid nanocomposites built from in-situ generated organically functionalized nanoanatase building blocks," Advanced Materials, vol. 15, no. 3, pp. 217-221, 2003.

[16] A. Singh, A. Joshi, S. Samanta et al., "Charge transport in polypyrrole: ZnO-nanowires composite films," Applied Physics Letters, vol. 95, no. 20, Article ID 202106, 2009.

[17] A. Joshi, D. K. Aswal, S. K. Gupta, J. V. Yakhmi, and S. A. Gangal, "ZnO-nanowires modified polypyrrole films as highly selective and sensitive chlorine sensors," Applied Physics Letters, vol. 94, no. 10, Article ID 103115, 2009.

[18] P. Somani, A. B. Mandale, and S. Radhakrishnan, "Study and development of conducting polymer-based electrochromic display devices," Acta Materialia, vol. 48, no. 11, pp. 2859-2871, 2000.

[19] M. G. Hosseini, R. Bagheri, and R. Najjar, "Electropolymerization of polypyrrole and polypyrrole- $\mathrm{ZnO}$ nanocomposites on mild steel and its corrosion protection performance," Journal of Applied Polymer Science, vol. 121, no. 6, pp. 3159-3166, 2011.

[20] R. Devi, M. Thakur, and C. S. Pundir, "Construction and application of an amperometric xanthine biosensor based on zinc oxide nanoparticles-polypyrrole composite film," Biosensors and Bioelectronics, vol. 26, no. 8, pp. 3420-3426, 2011.
[21] Y. Hao, M. Yang, W. Li, X. Qiao, L. Zhang, and S. Cai, "Photoelectrochemical solar cell based on $\mathrm{ZnO} /$ dye/polypyrrole film electrode as photoanode," Solar Energy Materials and Solar Cells, vol. 60, no. 4, pp. 349-359, 2000.

[22] M. R. Mahmoudian, W. J. Basirun, Y. Alias, and A. Khorsand Zak, "Electrochemical characteristics of coated steel with poly $(N$-methyl pyrrole) synthesized in presence of $\mathrm{ZnO}$ nanoparticles," Thin Solid Films, vol. 520, no. 1, pp. 258-265, 2011.

[23] Y. Chen, Z. Zhao, and C. Zhang, "Structural and electrochemical study of polypyrrole/ZnO nanocomposites coating on nickel sheet synthesized by electrochemical method," Synthetic Metals, vol. 163, pp. 51-56, 2013.

[24] A. Olad and R. Nosrati, "Preparation and corrosion resistance of nanostructured PVC/ZnO-polyaniline hybrid coating," Progress in Organic Coatings, vol. 76, no. 1, pp. 113-118, 2013.

[25] D. Ghosh, P. S. Sardar, M. Biswas, A. Mondal, and N. Mukherjee, "Dielectric characteristics of poly( $N$-vinylcarbazole) and its nanocomposites with $\mathrm{ZnO}$ and acetylene black," Materials Chemistry and Physics, vol. 123, no. 1, pp. 9-12, 2010.

[26] J. Kim, D. Sohn, Y. Sung, and E.-R. Kim, "Fabrication and characterization of conductive polypyrrole thin film prepared by in situ vapor-phase polymerization," Synthetic Metals, vol. 132, no. 3, pp. 309-313, 2003.

[27] D. L. Pavia, G. M. Lampman, and G. S. Kriz, Introduction To Spectroscopy: A Guide For Students of Organic Chemistry, Saunders Golden Sunburst Series, Saunders College Publishing, 1996.

[28] I. Belaish, D. Davidov, H. Selig, M. R. McLean, and L. Dalton, "Spatially selective conducting patterns in transparent films derived from ladder type polymers," Angewandte Chemie: International Edition in English, vol. 28, no. 11, pp. 1569-1577, 1989.

[29] A. Eftekhari, Nanostructured Conducting Polymers, Wiley, 2010.

[30] B. D. Mert and B. Yazici, "The electrochemical synthesis of poly(pyrrole-co-o-anisidine) on 3102 aluminum alloy and its corrosion protection properties," Materials Chemistry and Physics, vol. 125, no. 3, pp. 370-376, 2011.

[31] A. Mollahosseini and E. Noroozian, "Electrodeposition of a highly adherent and thermally stable polypyrrole coating on steel from aqueous polyphosphate solution," Synthetic Metals, vol. 159, no. 13, pp. 1247-1254, 2009.

[32] J.-C. Lacroix, J.-L. Camalet, S. Aeiyach et al., "Aniline electropolymerization on mild steel and zinc in a two-step process," Journal of Electroanalytical Chemistry, vol. 481, no. 1, pp. 76-81, 2000.

[33] A. Yaǧan, N. Ö. Pekmez, and A. Yildiz, "Electrochemical synthesis of poly $(N$-methylaniline) on an iron electrode and its corrosion performance," Electrochimica Acta, vol. 53, no. 16, pp. 5242-5251, 2008.

[34] G. Bereket and E. Hür, "The corrosion protection of mild steel by single layered polypyrrole and multilayered polypyrrole/poly(5-amino-1-naphthol) coatings," Progress in Organic Coatings, vol. 65, no. 1, pp. 116-124, 2009.

[35] P. Ocón, A. B. Cristobal, P. Herrasti, and E. Fatas, "Corrosion performance of conducting polymer coatings applied on mild steel," Corrosion Science, vol. 47, no. 3, pp. 649-662, 2005.

[36] M. Pourbaix, Atlas of Electrochemical Equilibria in Aqueous Solutions, National Association of Corrosion Engineers, 1974.

[37] D. Ichinohe, T. Muranaka, T. Sasaki, M. Kobayashi, and H. Kise, "Oxidative polymerization of phenylenediamines catalyzed by horseradish peroxidase," Journal of Polymer Science A: Polymer Chemistry, vol. 36, no. 14, pp. 2593-2600, 1998. 
[38] P. Pawar, A. B. Gaikwad, and P. P. Patil, "Corrosion protection aspects of electrochemically synthesized poly(o-anisidine-coo-toluidine) coatings on copper," Electrochimica Acta, vol. 52, no. 19, pp. 5958-5967, 2007.

[39] B. N. Grgur, P. Živković, and M. M. Gvozdenović, "Kinetics of the mild steel corrosion protection by polypyrrole-oxalate coating in sulfuric acid solution," Progress in Organic Coatings, vol. 56, no. 2-3, pp. 240-247, 2006.

[40] H. Wei, D. Ding, X. Yan et al., Tungsten Trioxide/Zinc Tungstate Bilayers: Electrochromic Behaviors, Energy Storage and Electron Transfer, Electrochimica Acta.

[41] S. S. Sathiyanarayanan, S. S. Azim, and G. Venkatachari, "A new corrosion protection coating with polyaniline- $\mathrm{TiO}_{2}$ composite for steel," Electrochimica Acta, vol. 52, no. 5, pp. 2068-2074, 2007.

[42] H. Wei, D. Ding, S. Wei, and Z. Guo, "Anticorrosive conductive polyurethane multiwalled carbon nanotube nanocomposites," Journal of Materials Chemistry A, vol. 1, no. 36, pp. 10805-10813, 2013.

[43] J. Zhu, S. Wei, I. Y. Lee et al., "Silica stabilized iron particles toward anti-corrosion magnetic polyurethane nanocomposites," RSC Advances, vol. 2, no. 3, pp. 1136-1143, 2012.

[44] F. Montilla, M. A. Cotarelo, and E. Morallón, "Hybrid sol-gelconducting polymer synthesised by electrochemical insertion: tailoring the capacitance of polyaniline," Journal of Materials Chemistry, vol. 19, no. 2, pp. 305-310, 2009.

[45] Y. Gao, C.-A. Chen, H.-M. Gau et al., "Facile synthesis of polyaniline-supported $\mathrm{Pd}$ nanoparticles and their catalytic properties toward selective hydrogenation of alkynes and cinnamaldehyde," Chemistry of Materials, vol. 20, no. 8, pp. 28392844, 2008.

[46] M. Selvaraj, S. Palraj, K. Maruthan, G. Rajagopal, and G. Venkatachari, "Synthesis and characterization of polypyrrole composites for corrosion protection of steel," Journal of Applied Polymer Science, vol. 116, no. 3, pp. 1524-1537, 2010.

[47] A. Szkurlat, B. Palys, J. Mieczkowski, and M. Skompska, "Electrosynthesis and spectroelectrochemical characterization of poly(3,4-dimethoxy-thiophene), poly(3,4-dipropyloxythiophene) and poly(3,4-dioctyloxythiophene) films," Electrochimica Acta, vol. 48, no. 24, pp. 3665-3676, 2003.

[48] M. A. Salam, S. S. Al-Juaid, A. H. Qusti, and A. A. Hermas, "Electrochemical deposition of a carbon nanotube-poly(ophenylenediamine) composite on a stainless steel surface," Synthetic Metals, vol. 161, no. 1-2, pp. 153-157, 2011. 

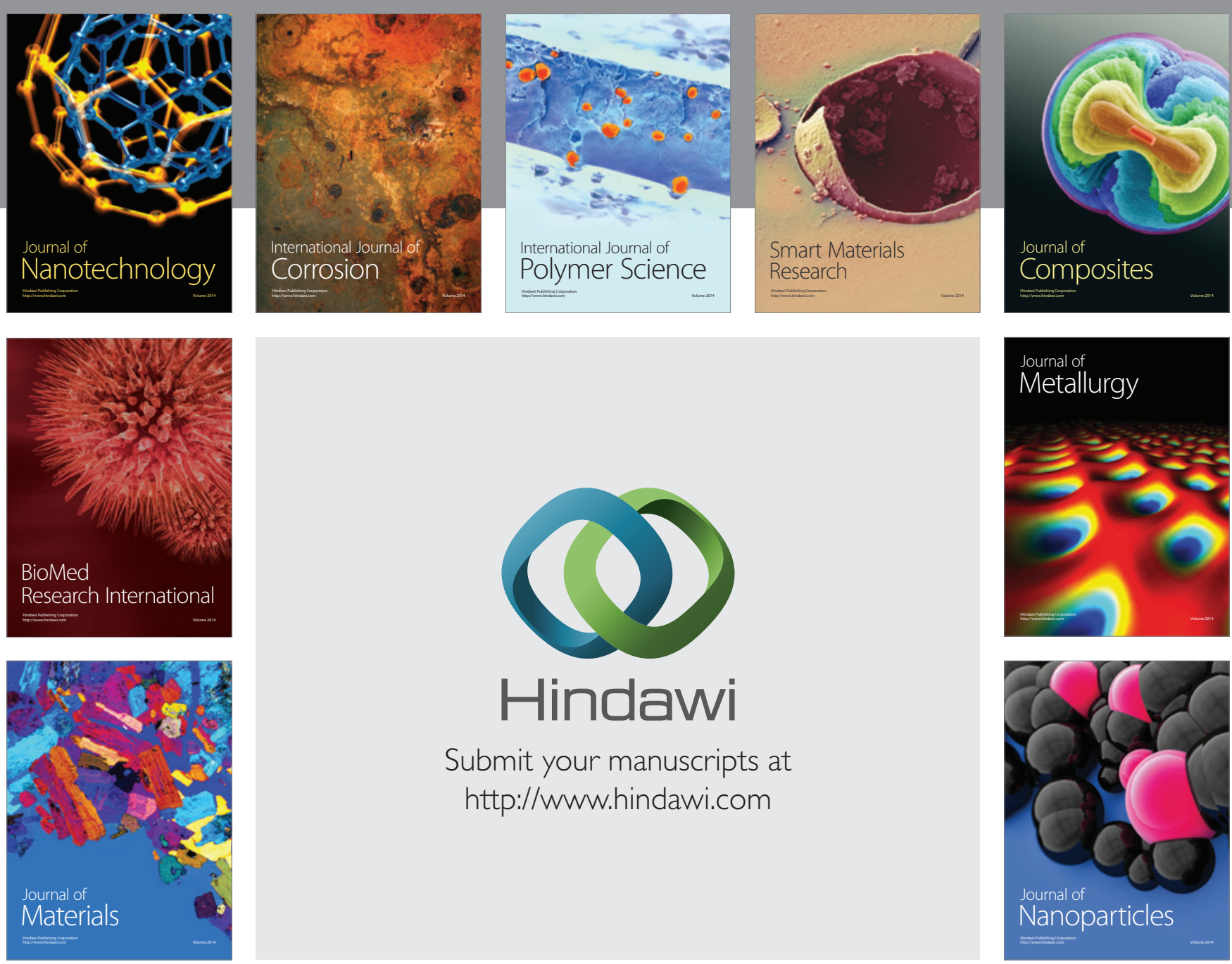

Submit your manuscripts at http://www.hindawi.com
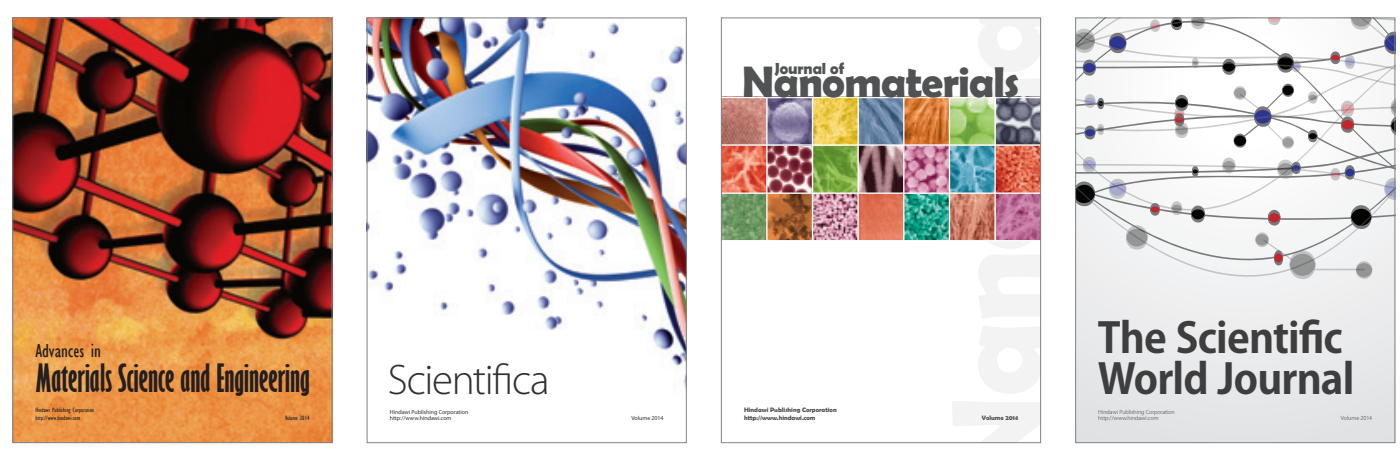

\section{The Scientific World Journal}
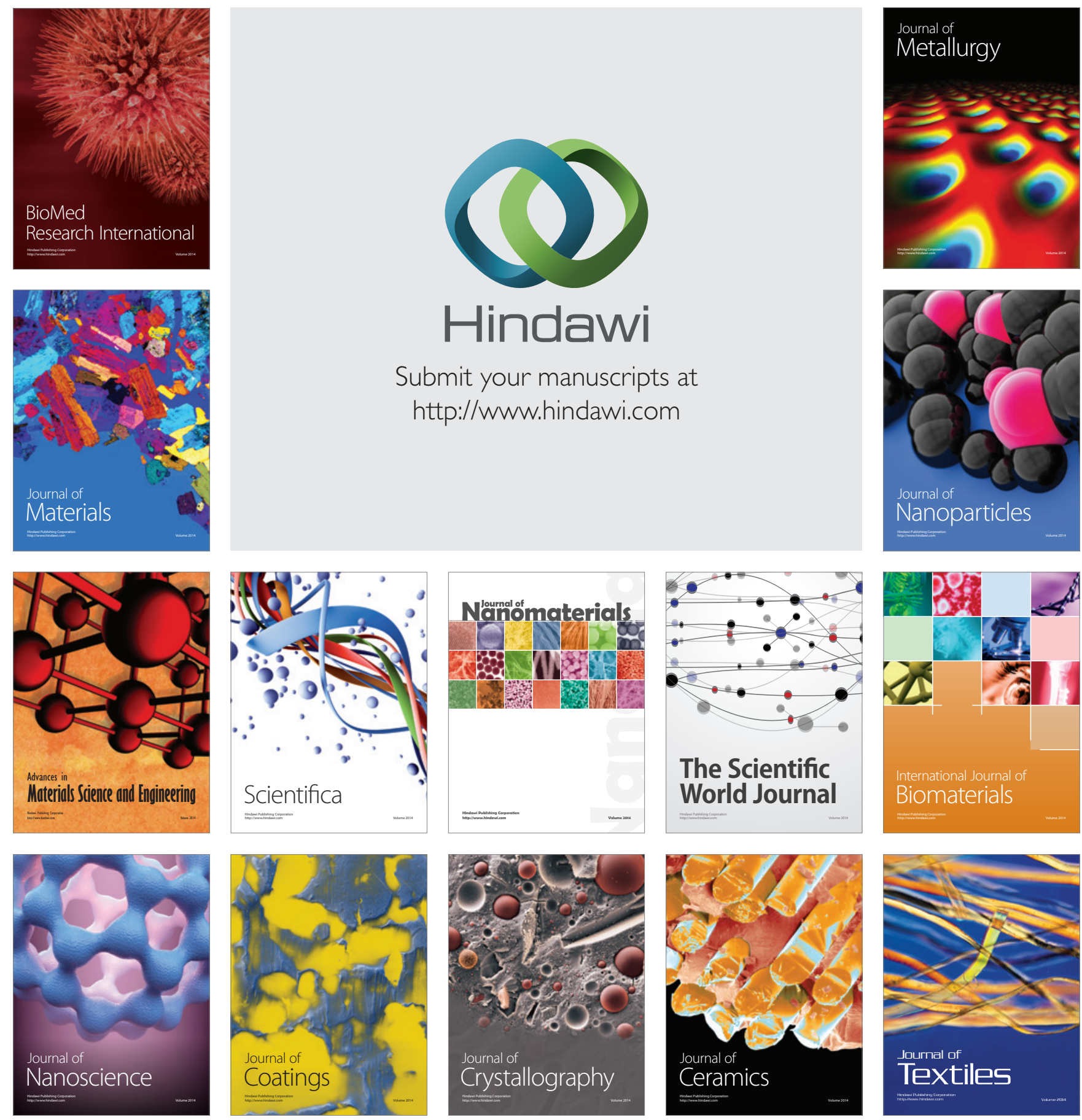